\title{
Reliability and Validity of the Adapted Chinese Version of the Satisfaction of Adolescents with Postoperative Pain Management - Idiopathic Scoliosis (SAP-S) Scale
}

This article was published in the following Dove Press journal:

Journal of Pain Research

\author{
Zheng Zhang ${ }^{1, *}$ \\ Miao $\mathrm{Hu}^{\mathrm{l}}$,* \\ Jingjing Chen ${ }^{2, *}$ \\ Tao Lin' \\ Jun $\mathrm{Ma}^{\prime}$ \\ Ce Wang' \\ Xuhui Zhou (D)' \\ Yichen Meng (D) \\ 'Department of Orthopedics, \\ Changzheng Hospital, Naval Medical \\ University, Shanghai, 200003, People's \\ Republic of China; ${ }^{2}$ Health Management \\ Center, Changzheng Hospital, Naval \\ Medical University, Shanghai, 200003, \\ People's Republic of China \\ *These authors contributed equally to \\ this work
}

Study Design: A prospective study.

Objective: The aim of this study was to evaluate the internal reliability and structure validity of an adapted simplified Chinese version of the Satisfaction of Adolescents with Postoperative pain management - idiopathic Scoliosis (SAP-S) scale in mainland China.

Summary of Background Data: Pain management is a major issue for adolescent idiopathic scoliosis (AIS) patients undergoing posterior spinal fusions. There is a lack of valid scales for evaluating patients' satisfaction with postoperative pain management. The SAP-S was proven to be a valid and reliable measure in English and French.

Methods: The SAP-S was translated into Chinese according to the internationally recognized guidelines. A total of 95 AIS patients undergoing posterior fusion surgery completed the CSAP-S, along with other self-reported questionnaires, including the 36-Item Short Form Health Survey (SF-36) and Scoliosis Research Society-22 (SRS-22) questionnaires. The internal consistency, test-retest reliability, and construct validity of the CSAP-S were determined.

Results: The SAP-S was successfully translated into Chinese. All patients completed the CSAP-S twice and the other instruments. The CSAP-S had good internal consistency and test-retest reliability with Cronbach's alpha coefficient measuring 0.895 and intraclass correlation coefficient (ICC) measuring 0.97. Elimination of any one item did not result in a value of Cronbach's alpha of $<0.80$. A good construct validity was shown by good correlation with bodily pain $(\mathrm{r}=0.883, \mathrm{p}=0.004)$ and social functioning $(\mathrm{r}=0.786, \mathrm{p}=0.002)$ domains of SF-36 and pain $(r=0.752, p=0.001)$ and satisfaction with management $(r=0.746$, $\mathrm{p}=0.005)$ domains of SRS-22.

Conclusion: The CSAP-S demonstrated good internal consistency, reliability, and construct validity, and may be used for the evaluation of AIS patients' satisfaction with postoperative pain management in mainland China.

Keywords: Chinese adaptation, idiopathic scoliosis, pain management, SAP-S, satisfaction

\section{Introduction}

Adolescent idiopathic scoliosis, characterized by a lateral spinal curvature with a Cobb's angle of greater than $10^{\circ}$ and vertebral rotation, is the most common spinal deformity affecting $2 \%$ children younger than 16 years of age. ${ }^{1}$ Currently, surgery still remains a main treatment strategy for AIS patients with Cobb's angle over 50 degrees. It is well understood that severe pain is often encountered by
Correspondence: Yichen Meng;

Xuhui Zhou

Tel +862181886999

Fax +862163520020

Email ycmengspine@smmu.edu.cn;

zhouxuhui@smmu.edu.cn
Journal of Pain Research 2021:14 953-960 
patients and typically lasts for at least three days after major spine surgery. ${ }^{2}$ Adolescents have been reported to have more pain than adults after surgery. ${ }^{3}$ And the pain experienced after scoliosis correction surgery has been described as severe and excruciating. ${ }^{4}$

Postoperative pain is not only a matter of worsened patient-oriented outcomes, it also substantially affects recovery, increases postoperative morbidities and prolongs the length of hospital stay. ${ }^{5}$ In a prospective cohort analysis conducted by Theologis et al, the data suggested AIS patients and their guardians had the best comprehension of postoperative pain management, which reflected the importance attached to pain by patients and guardians. ${ }^{6}$ A trial by Chan et al also demonstrated that pain was the greatest concern for AIS patients and parents prior to correction surgery. ${ }^{7}$ Therefore, adequate postoperative pain management indicates higher patient satisfaction and better clinical outcomes. Furthermore, patient's satisfaction was also found to be strongly correlated with the perception that health care professionals did everything they could to control their pain. ${ }^{8}$ Thus, well-designed and reliable questionnaires should be developed to measure the patient's satisfaction with postoperative pain management.

Scoliosis Research Society (SRS) Outcomes Instrument has been an accepted health-related-quality-oflife questionnaire to evaluate the perception of patients with spinal deformities of their status. ${ }^{9}$ However, no item in this questionnaire is specifically related to the quality of postoperative pain management. The Satisfaction of Adolescents with Postoperative pain management - idiopathic Scoliosis (SAP-S) scale is a newly developed measure assessing patient's satisfaction with postoperative pain management following idiopathic scoliosis surgery. This measure was initially developed and validated in French by Khadra et al (unpublished data, 2016). Shortly afterwards, an English version of SAP-S scale was proved to be a valid and reliable measure of satisfaction with postoperative pain management for adolescents undergoing correction surgery. ${ }^{10}$ However, it has not been carried out in the Chinese. According to the 2010 national population census, China had a total population of 1.34 billion, with population under the age of 15 accounting for $16.60 \% .^{11}$ And several school screening studies reported the incidence rate of AIS in China ranged from $0.22 \%$ to $5.14 \%{ }^{12-15}$ There has been no existing measure concerning pain management for this large patient population so far. As Chinese people are culturally distinct from
Caucasian people, it was felt important to adapt and translate the SAP-S scale into Chinese and to validate it before use.

The purpose of this study was to translate and adapt the SAP-S into a simplified Chinese version (CSAP-S) and evaluate its psychometric properties.

\section{Materials and Methods}

This study was approved by the Institutional Review Board of Shanghai Changzheng Hospital before initiation, and conducted in accordance with the Declaration of Helsinki. Written informed consent was obtained from all participants' parents or legal guardians.

The SAP-S scale (English version) originally includes six domains which have been introduced in detail by Khadra et al. ${ }^{10}$ It was adapted into Chinese according to the recommended protocol issued by the American Association of Orthopedic Surgeon (AAOS) Outcomes committee and outlined by Beaton et al. ${ }^{16}$ Two translators independently translated the English version of the SAP-S scale into Chinese. After comparing the two translations, discrepancies were identified and resolved by consensus. Two back-translations were performed by two other translators, without reference to the original SAP-S scale. The back-translators were neither aware nor informed of the outcome measurement in this study. All translators were bilingual, with a good command of both English and Chinese. The final form of the Chinese translation of the SAP-S scale was a consensus reached by an expert committee who are similarly bilingual and are familiar with spinal deformity.

\section{Participants}

Successive AIS patients in Shanghai Changzheng Hospital from July 2018 to July 2019 were prospectively enrolled in the study. The inclusion criteria were (1) age between 12 and 18 years, (2) who were diagnosed with AIS and underwent posterior spinal instrumentation and fusion of over 4 levels, (3) who were Chinese literate. The exclusion criteria were (1) who were unable to read Chinese, (2) presence of any cord and vertebra anomaly as demonstrated on a whole spine magnetic resonance imaging, (3) who had a history of previous spinal surgery. The CSAP-S scale was first mailed and completed by the included participants at two weeks post-discharge. To explore the adaptation of CSAP-S, test-retest reliability assessment was conducted. The patients were instructed to complete an identical scale a second time by email in ten days' time. 
Table I Participant Demographic and Clinical Characteristics

\begin{tabular}{|c|c|c|c|c|}
\hline General Characteristics & $\mathbf{N}$ & Minimum & Maximum & Mean \\
\hline Age (yo) & 95 & 12 & 18 & $14.7 \pm 1.8$ \\
\hline Sex (Female) & 77 & & & \\
\hline Height (cm) & 95 & 136.3 & 178.2 & $159.8 \pm 1 \mid .7$ \\
\hline Body weight (kg) & 95 & 29.8 & $6 I .1$ & $47.4 \pm 10.5$ \\
\hline Risser stage & I (4), 2 (8), 3 (8), 4 (29), 5 (46) & & & \\
\hline Lenke curve type & I (38), 2 (20), 3 (I2), 4 (5), 5 (I3), 6 (7) & & & \\
\hline Preoperative Cobb angle of major curve $\left({ }^{\circ}\right)$ & 95 & 46 & 69 & $55.2 \pm 7.3$ \\
\hline Flexibility of major curve (\%) & 95 & 26 & 58 & $42.1 \pm 10.4$ \\
\hline Postoperative Cobb angle of major curve $\left({ }^{\circ}\right)$ & 95 & 3 & 23 & $12.7 \pm 3.5$ \\
\hline Correction rate & 95 & 64.3 & 93.2 & $79.6 \pm 11.4$ \\
\hline Fusion level & 95 & 6 & 16 & $9.6 \pm 3.2$ \\
\hline Duration of surgery (minutes) & 95 & 224 & 473 & $332.1 \pm 82.3$ \\
\hline Screw density & 95 & 1 & 2 & $1.4 \pm 0.4$ \\
\hline Length of hospital stay (days) & 95 & 4 & 10 & $6.3 \pm 1.6$ \\
\hline Complications & 6 & & & \\
\hline Transient neurological deficit & 1 & & & \\
\hline Pulmonary infection & 2 & & & \\
\hline Wound dehiscence & 1 & & & \\
\hline Superficial wound infection & 2 & & & \\
\hline
\end{tabular}

Note: Flexibility of the major curve was calculated as Cobb's angle on standing view - Cobb's angle on side bending view/Cobb's angle on standing view $\times$ I00.

The SAP-S scale consists of six sections from A to F and only the 13-item satisfaction subscale in section B was suitable for the further assessment. ${ }^{10}$ Section $\mathrm{B}$ is designed to rate the patient's level of satisfaction and importance with pain management and the information they received about pain management and recovery during hospitalization. The score for each item ranges from 1 (least satisfied/ least important) to 6 (very satisfied/very important).

\section{Statistical Analysis}

Regarding content analysis, for each item in the scale, the mean, standard deviation, and range were calculated. Floor and ceiling effects exceeding $15 \%$ were considered to be significant. ${ }^{17}$ Cronbach's alpha was used to evaluate internal consistency, and $>0.8$ were considered as good internal consistency. The test-retest reliability was measured by comparing responses to the two different administrations of CSAP-S. It was assessed by the intra-class correlation coefficient (ICC). An ICC value between 0.7 and 0.8 indicates good reliability, and more than 0.8 indicates excellent reliability. ${ }^{18}$ Construct validity was evaluated through a principal component analysis (PCA) using varimax rotation. The Kaiser-Meyer-Olkin (KMO) measure of sampling adequacy and the Bartlett's test of sphericity were conducted prior to running the analysis. ${ }^{10}$ Also, CSAP-S items were compared with relevant dimensions from well validated Chinese version of 36-Item Short Form Health Survey $(\mathrm{SF}-36)^{19}$ and Scoliosis Research Society-22 (SRS-22) ${ }^{20}$ questionnaires. They were sent to the patients with CSAPS concomitantly. Correlation was made using Pearson correlation coefficients. A Pearson correlation coefficient of more than 0.75 is considered excellent, 0.5 to 0.75 as good, 0.25 to 0.5 as fair, and less than 0.25 as poor. Statistical analysis was performed using the Statistical 
Package for the Social Sciences (SPSS) version 24.0 (SPSS, Chicago, IL). Mean values were reported with standard deviation (SD), and ICC values were presented with $95 \%$ confidence intervals (CIs). A P value of $<0.05$ was considered statistically significant.

\section{Results}

\section{Patients}

A total of 95 AIS patients participated and completed the study. There were 77 females and 18 males. All the patients were scheduled for posterior all-pedicle screw instrumentation and fusion. We excluded patients treated with growing rods or anterior approach. The average elapsed time between the first and the second mailing was 8 days (range: $7-10$ days). Patient characteristics and demographics are summarized in Table 1.

\section{Cross-Cultural Adaptation}

There were no major language problems occurred in the forward and backward translations process. All the patients and their guardians were able to finish the questionnaire without any difficulties, which indicated that the CSAP-S was well cross-cultural inherited and easy to be understood.

\section{Score Distribution}

The distribution of scores for 13-item satisfaction subscale was demonstrated in Table 2. All of the items showed a low level of floor and ceiling effect $(<15 \%)$. The values of skewness and kurtosis were $<1.92$ for each item, showing that all items had a normal distribution.

\section{Reliability}

The internal consistency of CSAP-S was good (Cronbach's alpha $=0.895$ ). The Cronbach's alpha remained to be $>0.80$ when elimination of each item in all 13 items. All items correlated with the total score with good result of item-total score correlation. The test-retest reliability of CSAP-S was also excellent. Mean score of the retest was $57.33 \pm 7.60$, which was comparable with the first test $(56.81 \pm 7.56)$. ICC for the overall CSAP-S was 0.97 (95\% CI, 0.95-0.98), and test-retest reliability of each question was good or excellent (ICC: range from 0.81 to 0.97 ) (Table 3). Bland and Altman plots for the two tests revealed no systematic bias, which suggested good test-retest agreement and reproducibility of CSAP$\mathrm{S}$ (Figure 1).

Table 2 Score Distribution and Internal Consistency of the CSAP-S

\begin{tabular}{|c|c|c|c|c|c|}
\hline Item & Value of Skewness & Value of Kurtosis & Cronbach's Alpha & Ceiling Effect (\%) & Floor Effect (\%) \\
\hline Total & -0.94 & 0.43 & 0.90 & 0 & 0 \\
\hline I & -0.63 & -0.26 & 0.88 & 0 & 7.37 \\
\hline 2 & -0.20 & -0.70 & 0.88 & 0 & 4.21 \\
\hline 3 & -0.62 & -0.34 & 0.88 & 0 & 5.26 \\
\hline 4 & -0.47 & 0.30 & 0.89 & 1.05 & 2.11 \\
\hline 5 & -0.54 & 0.12 & 0.89 & 0 & 6.32 \\
\hline 6 & -0.78 & 0.34 & 0.89 & 0 & 9.47 \\
\hline 7 & -0.80 & 0.28 & 0.89 & 0 & 10.53 \\
\hline 8 & -0.52 & 0.26 & 0.89 & 0 & 7.37 \\
\hline 9 & -0.40 & -0.01 & 0.89 & 0 & 6.32 \\
\hline 10 & -0.10 & -0.38 & 0.89 & 0 & 10.53 \\
\hline II & -0.27 & -0.92 & 0.89 & 0 & 8.42 \\
\hline 12 & -0.33 & -0.03 & 0.89 & 0 & 6.32 \\
\hline 13 & -0.42 & -0.07 & 0.89 & 0 & 4.21 \\
\hline
\end{tabular}

Notes: Cronbach's alpha was calculated for each item when this item was removed. CSAP-S, Chinese version of the Satisfaction of Adolescents with Postoperative pain management - idiopathic Scoliosis scale. 
Table 3 Test-Retest Reliability and Distribution of the CSAP-S

\begin{tabular}{|c|c|c|c|c|c|}
\hline \multirow[t]{2}{*}{ Item } & \multicolumn{2}{|c|}{ First Test } & \multicolumn{2}{|c|}{ Second Test } & \multirow[t]{2}{*}{ ICC (Cls Range) } \\
\hline & Mean \pm SD & Range & Mean \pm SD & Range & \\
\hline Total & $57.33 \pm 7.60$ & $35-69$ & $56.8 I \pm 7.56$ & $35-68$ & $0.97(0.95-0.98)$ \\
\hline I & $4.38 \pm 0.99$ & $2-6$ & $4.24 \pm 0.99$ & $1-6$ & $0.86(0.80-0.91)$ \\
\hline 2 & $4.34 \pm 0.81$ & $3-6$ & $4.17 \pm 0.86$ & $2-6$ & $0.8 \mathrm{I}(0.72-0.87)$ \\
\hline 3 & $4.26 \pm 1.01$ & $2-6$ & $4.19 \pm 1.09$ & $1-6$ & $0.87(0.8 I-0.9 I)$ \\
\hline 4 & $4.06 \pm 0.91$ & $1-6$ & $3.97 \pm 0.91$ & $1-6$ & $0.87(0.8 \mathrm{I}-0.9 \mathrm{I})$ \\
\hline 5 & $4.37 \pm 0.90$ & $2-6$ & $4.33 \pm 0.96$ & $2-6$ & $0.90(0.86-0.93)$ \\
\hline 6 & $4.7 I \pm 0.78$ & $3-6$ & $4.69 \pm 0.85$ & $2-6$ & $0.90(0.85-0.93)$ \\
\hline 7 & $4.72 \pm 0.8 \mathrm{I}$ & $3-6$ & $4.67 \pm 0.78$ & $3-6$ & $0.90(0.85-0.93)$ \\
\hline 8 & $4.53 \pm 0.81$ & $2-6$ & $4.49 \pm 0.87$ & $2-6$ & $0.89(0.84-0.92)$ \\
\hline 9 & $4.44 \pm 0.82$ & $2-6$ & $4.43 \pm 0.77$ & $2-6$ & $0.87(0.82-0.91)$ \\
\hline 10 & $4.57 \pm 0.79$ & $3-6$ & $4.49 \pm 0.76$ & $3-6$ & $0.87(0.8 \mathrm{I}-0.9 \mathrm{I})$ \\
\hline 11 & $4.16 \pm 1.12$ & $2-6$ & $4.25 \pm 1.04$ & $2-6$ & $0.91(0.87-0.94)$ \\
\hline 12 & $4.42 \pm 0.82$ & $2-6$ & $4.45 \pm 0.82$ & $2-6$ & $0.91(0.87-0.94)$ \\
\hline 13 & $4.38 \pm 0.80$ & $2-6$ & $4.43 \pm 0.77$ & $3-6$ & $0.92(0.89-0.95)$ \\
\hline
\end{tabular}

Abbreviations: ICC, intraclass correlation coefficient; Cls, confidence intervals.

\section{Validity}

Content validity of the scale was first evaluated by clinical experts on pain management. And information derived from all items was adequate to assess patient's satisfaction with postoperative pain management following posterior spinal instrumentation and fusion. Therefore, no item was recommended to be removed.

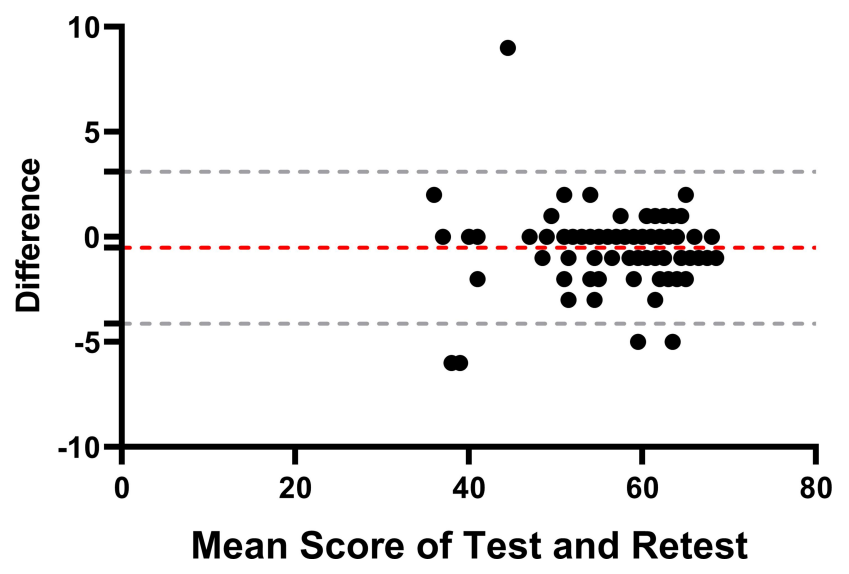

Figure I The Bland-Altman plot for test-retest agreement of the CSAP-S. The grey dashed line indicates the $95 \%$ ( \pm 1.96 standard deviation) limits of agreement.
The value of KMO was 0.873 and the Bartlett's test result was $p<0.000$. Similar to Khadra's results, ${ }^{10}$ PCA analysis indicated a three-factor structure of the 13-item satisfaction subscale of the SAP-S scale, which was confirmed by the scree plot of the eigenvalues (Figure 2). The factor structure referred to information received after surgery (Factor 1), satisfaction regarding current medication received (Factor 2) and actions taken by nurses and doctors to manage pain (Factor 3). Although Item 4, 6 and 10 showed similar loads in any two of the three factors, Item 4 was added to Factor 1, and Item 6 and 10 were added to Factor 3 as the content of the item was more related to the respective Factor. Detailed results are presented in Table 4.

Table 5 lists the data of construct validity of CSAP-S. The results revealed that CSAP-S was well correlated with bodily pain $(\mathrm{r}=0.883, \mathrm{p}=0.004)$, role-physical $(\mathrm{r}=0.664$, $\mathrm{p}=0.019)$ and social functioning $(\mathrm{r}=0.786, \mathrm{p}=0.002)$ domains of SF-36 and pain $(r=0.752, p=0.001)$ and satisfaction with management $(r=0.746, p=0.005)$ domains of SRS-22. The correlations between CSAP-S and physical functioning, general health perceptions and vitality domains of SF-36 and function and self-image domains of SRS-22 were moderate. Meanwhile, the CSAP-S was 


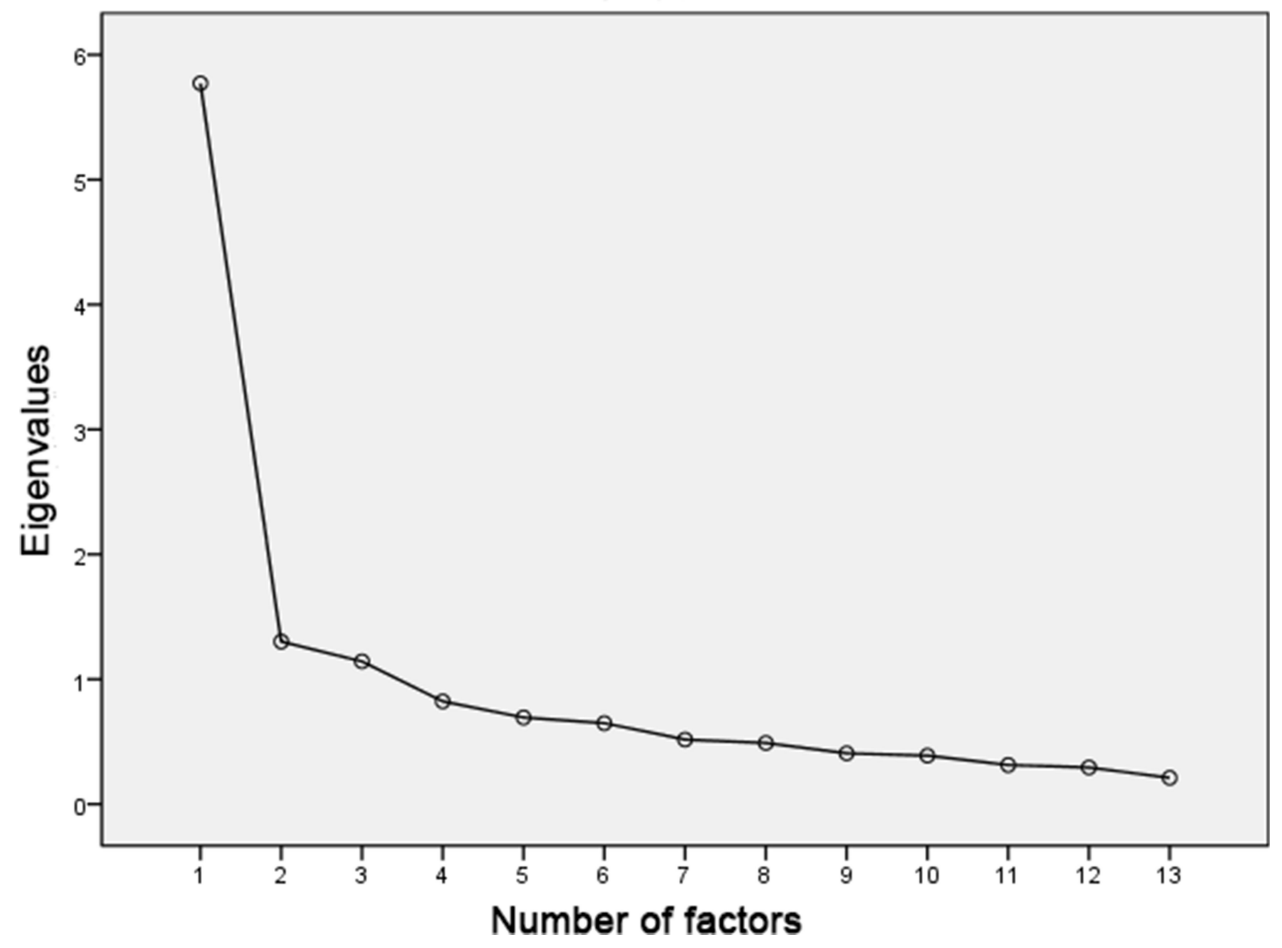

Figure 2 Scree plot to determine the number of factors to retain.

fairly correlated to the mental and role-emotional domains of SF-36 and mental domain of SRS-22. Overall, these results suggested that the CSAP-S had a good validity.

\section{Patient-Reported Outcomes of Other Sections}

In consistent with the previous study, ${ }^{10}$ constipation/ abdominal pain was the most frequently reported side effect (82.2\%). Strange unpleasant sensations (feeling different than usual) were the second most frequently reported side effect (64\%) and the description of the sensations varied greatly from patient to patient. Patientcontrolled analgesia was the most acceptable route for medication, with a mean of 5.3/6 $( \pm 1.1)$ for satisfaction. The rectal route had the lowest satisfaction score (mean of $2.1 \pm 1.7)$. Participants' average pain intensity dropped from $6.8 \pm 2.1$ a week ago to $3.1 \pm 1.9$ now. Twenty-one (22.1\%) patients reported relieving pain during hospitalization by listening to music. There were also some patients who diverted their attention by doing other things to relieve the pain.

\section{Discussion}

Pain management is a major issue for AIS patients undergoing spinal fusion surgery. There is no specific scale available in China that can be used to evaluate AIS patients' satisfaction with postoperative pain management. Only some health-related-quality-of-life questionnaires such as SF-36 and SRS-22, measuring perception of patients of their status are available in Chinese version. ${ }^{19,20}$ SAP-S, the scale to evaluate AIS patients' satisfaction with postoperative pain management, has been proven to be reliable and valid in French and English version. ${ }^{10}$ In this study, we have successfully produced a Chinese version of SAP-S scale by translation and adapted it with a satisfactory reliability and validity.

In our study, all the participants completed the CSAP-S twice. No ceiling and floor effect was found.

Regarding the internal consistency, although the present overall Cronbach's alpha was slightly lower than the original study (0.895 vs 0.91$)$, we considered this difference was due to differences in living habits of people of different cultures, rather than translation problems.

In test/retest reliability, an average time gap of 8 days for the two separated measurements helped minimize the influence of possible memory effect and clinical treatment effect. Furthermore, all domains had a value of more than 0.80 , demonstrating satisfactory or excellent test/retest reproducibility. 
Table 4 Factor Loadings from Principal Component Analysis with Varimax Rotation

\begin{tabular}{|c|c|c|c|}
\hline \multirow[t]{2}{*}{ Items } & \multicolumn{3}{|c|}{ Factors } \\
\hline & $\mathbf{I}$ & 2 & 3 \\
\hline $\begin{array}{l}\text { 2: The information about medication used to } \\
\text { reduce pain }\end{array}$ & 0.81 & 0.27 & 0.06 \\
\hline I: The information about the intensity of pain & 0.79 & 0.34 & 0.18 \\
\hline $\begin{array}{l}\text { 5: The information about medications used } \\
\text { when returning home and their side effects }\end{array}$ & 0.71 & 0.11 & 0.28 \\
\hline $\begin{array}{l}\text { 3: The information about the way to measure } \\
\text { pain with a pain scale }\end{array}$ & 0.68 & 0.15 & 0.33 \\
\hline $\begin{array}{l}\text { 4: The information about side effects you } \\
\text { could have (eg, nausea, itching, etc) }\end{array}$ & 0.58 & 0.46 & 0.07 \\
\hline $\begin{array}{l}\text { 13: The duration of pain relief the medication } \\
\text { brings you }\end{array}$ & 0.23 & 0.77 & 0.15 \\
\hline $\begin{array}{l}\text { II: The length of time the medication takes } \\
\text { before relieving the pain }\end{array}$ & 0.10 & 0.75 & 0.37 \\
\hline $\begin{array}{l}\text { 12: The amount of pain relief the medication } \\
\text { brings you }\end{array}$ & 0.32 & 0.72 & 0.17 \\
\hline 10: Treating your pain until its relieved & 0.40 & 0.45 & 0.18 \\
\hline $\begin{array}{l}\text { 8: Asking you questions about pain you are } \\
\text { feeling when you breathe deeply, when you sit } \\
\text { or when you move around }\end{array}$ & 0.03 & 0.35 & 0.74 \\
\hline $\begin{array}{l}\text { 9: Asking you about your pain level on a scale } \\
\text { of } 1-10 \text {, every morning, afternoon and } \\
\text { evening }\end{array}$ & 0.16 & 0.25 & 0.72 \\
\hline $\begin{array}{l}\text { 7: Helping you find a comfortable position in } \\
\text { your bed in order to reduce pain }\end{array}$ & 0.24 & 0.17 & 0.70 \\
\hline $\begin{array}{l}\text { 6: Believing you when you talk to them about } \\
\text { your pain }\end{array}$ & 0.49 & -0.05 & 0.67 \\
\hline
\end{tabular}

PCA was performed to verify the construct validity. The result suggested a three-factor model of the satisfaction subscale of the SAP-S scale was fit for mainland China, which was consistent with the French and English versions. All items loaded on either one of the three factors with the exception of item 4, 6 and 10. And they were moved to respective Factor based on the content. Pearson correlation was also used to compare the construct validity of the CSAP-S to other instruments including SF36 and SRS-22. The correlation between CSAP-S and pain domains was the strongest in our study ( $\mathrm{r}=0.883$ for SF-36 and 0.752 for SRS-22, respectively; very good). One possible reason might be that both domains were designed for
Table 5 Construct Validity of the Simplified Chinese Version of SAP-S

\begin{tabular}{|l|l|l|}
\hline Scales & $\begin{array}{l}\text { Correlation } \\
\text { Coefficient } \\
(\mathbf{r})\end{array}$ & P value \\
\hline SF-36 domain & 0.589 & 0.010 \\
Physical functioning & 0.664 & 0.019 \\
Role-physical & 0.883 & 0.004 \\
Bodily pain & 0.507 & 0.032 \\
General health perceptions & 0.596 & 0.041 \\
Vitality & 0.786 & 0.002 \\
Social functioning & 0.203 & 0.526 \\
Role-emotional & 0.378 & 0.099 \\
Mental health index & & \\
\hline SRS-22 domain & 0.599 & 0.039 \\
Function/activity & 0.752 & 0.001 \\
Pain & 0.523 & 0.081 \\
Self-image/appearance & 0.322 & 0.307 \\
Mental health & 0.746 & 0.005 \\
Satisfaction with management & &
\end{tabular}

evaluation of pain. Moreover, the CSAP-S was fairly correlated with the role emotional and mental domains, indicating the convergent and discriminant validity of the CSAP-S. Taken together, these findings suggest good construct validity of the CSAP-S.

Some potential limitations of this study should be considered. First, some authors would suggested that a sample size of at least 200 patients was required to be able to generalize results. ${ }^{10,21}$ The sample in the present study was limited in size and all the participants were recruited in a single institution. Thus, the sample may not fully represent the diverse Chinese population. Second, most of the participants were female as females were more likely to be affected by AIS.

\section{Conclusion}

In conclusion, this Chinese version of the SAP-S is the first specific scale for evaluating AIS patients' satisfaction with postoperative pain management to be validated in a Chinese population. The results of this study showed that the translated Chinese version of the SAP-S is an internally consistent, reliable and valid scale, which could be used for both research and clinical purposes. The present work will promote the use of CSAP-S in mainland China and by using it, improve the postoperative pain management for AIS patients undergoing posterior spinal fusion surgery. 


\section{Acknowledgment}

Satisfaction of Adolescents with Postoperative pain management-idiopathic Scoliosis (SAP-S): Copyright (C2013. Dove Medical Press. Reproduced from Khadra C, Le May S, Ballard A, et al. Validation of the scale on Satisfaction of Adolescents with Postoperative pain management - idiopathic Scoliosis (SAP-S). J Pain Res. 2017;10:137-43. ${ }^{10}$

\section{Funding}

There is no funding to report.

\section{Disclosure}

The authors report no conflicts of interest in this work.

\section{References}

1. Hresko MT. Clinical practice. Idiopathic scoliosis in adolescents. N Engl J Med. 2013;368(9):834-841. doi:10.1056/NEJMcp1209063

2. Bianconi M, Ferraro L, Ricci R, et al. The pharmacokinetics and efficacy of ropivacaine continuous wound instillation after spine fusion surgery. Anesth Analg. 2004;98:166-72, table of contents. doi:10.1213/01.ANE.0000093310.47375.44

3. Gillies ML, Smith LN, Parry-Jones WL. Postoperative pain assessment and management in adolescents. Pain. 1999;79(2):207-215. doi:10.1016/S0304-3959(98)00178-X

4. Borgeat A, Blumenthal S. Postoperative pain management following scoliosis surgery. Curr Opin Anaesthesiol. 2008;21(3):313-316. doi:10.1097/ACO.0b013e3282f82baa

5. Kehlet H. Postoperative pain relief-what is the issue? Br J Anaesth. 1994;72(4):375-378. doi:10.1093/bja/72.4.375

6. Theologis AA, Anaya A, Sabatini C, et al. Surgical consent of children and guardians for the treatment of adolescent idiopathic scoliosis is incompletely informed. Spine. 2016;41(1):53-61. doi:10.1097/ BRS.000000000001162

7. Chan P, Skaggs D, Sanders A, et al. Pain is the greatest preoperative concern for patients and parents prior to posterior spinal fusion for adolescent idiopathic scoliosis. Spine. 2017;42(21):E1245-E1250. doi:10.1097/BRS.0000000000002147

8. Hanna MN, Gonzalez-Fernandez M, Barrett AD, et al. Does patient perception of pain control affect patient satisfaction across surgical units in a tertiary teaching hospital? Am J Med Qual. 2012;27 (5):411-416. doi:10.1177/1062860611427769
9. Haher TR, Gorup JM, Shin TM, et al. Results of the Scoliosis Research Society instrument for evaluation of surgical outcome in adolescent idiopathic scoliosis. A multicenter study of 244 patients. Spine. 1999;24(14):1435-1440. doi:10.1097/00007632-19990715000008

10. Khadra C, Le May S, Ballard A, et al. Validation of the scale on Satisfaction of Adolescents with Postoperative pain management idiopathic Scoliosis (SAP-S). J Pain Res. 2017;10:137-143. doi:10.2147/JPR.S124365

11. The 6th National Population Census. Available from: http://www. stats.gov.cn/ztjc/zdtjgz/zgrkpc/dlcrkpc/dcrkpcyw/201104/t20110428 69407.htm. Accessed April 28, 2011.

12. Du Q, Zhou X, Negrini S, et al. Scoliosis epidemiology is not similar all over the world: a study from a scoliosis school screening on Chongming Island (China). BMC Musculoskelet Disord. 2016;17 (1):303. doi:10.1186/s12891-016-1140-6

13. Hengwei F, Zifang H, Qifei W, et al. Prevalence of idiopathic scoliosis in Chinese Schoolchildren: a Large, Population-Based Study. Spine. 2016;41(3):259-264. doi:10.1097/BRS.0000000000001197

14. Zhang H, Guo C, Tang M, et al. Prevalence of scoliosis among primary and middle school students in Mainland China: a systematic review and meta-analysis. Spine. 2015;40(1):41-49. doi:10.1097/BRS.0000000000000664

15. Zheng Y, Wu X, Dang Y, et al. Prevalence and determinants of idiopathic scoliosis in primary school children in Beitang district, Wuxi, China. J Rehabil Med. 2016;48(6):547-553. doi:10.2340/ 16501977-2098

16. Beaton DE, Bombardier C, Guillemin F, et al. Guidelines for the process of cross-cultural adaptation of self-report measures. Spine. 2000;25(24):3186-3191. doi:10.1097/00007632-200012150-00014

17. Terwee CB, Bot SD, de Boer MR, et al. Quality criteria were proposed for measurement properties of health status questionnaires. J Clin Epidemiol. 2007;60(1):34-42. doi:10.1016/j. jclinepi.2006.03.012

18. Landis JR, Koch GG. The measurement of observer agreement for categorical data. Biometrics. 1977;33(1):159-174. doi:10.2307/2529310

19. Ren XS, Amick B 3rd, Zhou L, et al. Translation and psychometric evaluation of a Chinese version of the SF-36 Health Survey in the United States. J Clin Epidemiol. 1998;51(11):1129-1138. doi:10.1016/S0895-4356(98)00104-8

20. Cheung KM, Senkoylu A, Alanay A, et al. Reliability and concurrent validity of the adapted Chinese version of Scoliosis Research Society-22 (SRS-22) questionnaire. Spine. 2007;32(10):1141-1145. doi:10.1097/01.brs.0000261562.48888.e3

21. Streiner DL, Norman GR, Cairney J. Health Measurement Scales: A Practical Guide to Their Development and Use. USA: Oxford University Press; 2014.
Journal of Pain Research

\section{Publish your work in this journal}

The Journal of Pain Research is an international, peer reviewed, open access, online journal that welcomes laboratory and clinical findings in the fields of pain research and the prevention and management of pain. Original research, reviews, symposium reports, hypothesis formation and commentaries are all considered for publication. The manuscript management system is completely online and includes a very quick and fair peer-review system, which is all easy to use. Visit http:// www.dovepress.com/testimonials.php to read real quotes from published authors. 